\title{
60
}

\section{New Media in Language Assessments}

\author{
Paul Gruba \\ University of Melbourne, Australia
}

New media, such as digital video clips, wikis, and podcasts, are integrated throughout an increasing number of second and foreign language programs, yet their use in language assessments continues to lag. In this chapter, I explore the role of new media in language assessments. After setting out key concepts, I begin with a brief review of computer-assisted language learning and computer-based testing. I then turn to issues in the use of new media in assessment for learning with regard to institutional resources, professional development, and educational policies. In a third section, I shift the focus to discuss the challenges of new media language assessments. I conclude with a proposed agenda to spur the integration of new media into language assessments.

\section{Introduction}

Increasingly, educators across the disciplines are urged to use new media in assessments to better prepare students to meet the demands of the 21st century (Wyatt-Smith \& Cumming, 2009). Indeed, in the early 2000s, Bennett (2002) argued that the use of technologies in assessments would be "inexorable and inevitable"; accordingly, Bennett argued, debate about their inclusion in testing would cease and efforts would come to focus on "how to do it responsibly, not only to preserve the validity, fairness, utility, and credibility of the measurement enterprise but, even more so, to enhance it" (p. 15).

Before further discussion, an overview of key concepts may be helpful. In this chapter, I follow Lievrouw (2011, p. 7) to view new media as a blend of information and communication technologies and their social contexts that includes: 
1) the material artifacts or devices that enable and extend people's abilities to communicate and share meaning;

2) the communication activities or practices that people engage in as they develop and use those devices; and

3) the larger social arrangements and organizational forms that people create and build around the artifacts and practices. (italics in the original)

In this view, "new media" is a term that attempts to bring together technologies, activities, and structures. As devices, new media are perhaps best symbolized by smartphones and multitouch tablet computers. The use of powerful new media devices influences the way people communicate across local and global networks. In their use of these devices, people are able to choose how to communicate, for example, through texting, talking, or sending images, and whether to communicate synchronously or asynchronously. Such usage fosters social participation, and each day hundreds of millions of people use new media to interact through forms such as chat lines, digital video clips, wikis, blogs, and podcasts. Collectively, the global use of new media has prompted large organizations to provide online services and interactions in areas that include "e-government," "e-commerce," and "e-learning." New media are now used to such an extent that core elements of language and discourse have changed (Herring, in press), and they increasingly shape the expectations and identities of language students (Higgins, 2011).

Perhaps subtly, any discussion of new media in language assessment must maintain a distinction between using new media to test language proficiency (e.g., as a device, technology, or platform for development and delivery) and seeing new media use as a required part of language skills (e.g., in writing a blog, speaking in a live streaming video, or creating a podcast). With regard to the former, Chapelle (2008) identifies three reasons to use technologies in assessment. First, practitioners may want to create assessments that are more efficient than paper and pencil formats. A second reason is to create equivalents of established paper and pencil formats that are not only reliable and valid, but also more efficient. A third reason is to innovate in ways that are fit for purpose, meet specific needs of a program, or best align with pedagogical approaches and intended outcomes. In this chapter, I focus on the third of these reasons to argue for a greater alignment of new media language teaching and assessment practices.

Discussions concerning the proficient use of new media by students can often be located alongside work to do with "media literacy" or "new literacies" skills that are seen to be an imperative in education to promote engaged citizenry and strong economies in an era of digital globalization (Coiro, Knobel, Lankshear, \& Leu, 2008). Scholars, however, have yet to establish a basis for the assessment of media literacy skills (Christ, 2004) as they continue to establish a range of concepts and issues (Potter, 2011). Throughout this chapter, I focus on "assessment for learning" defined as "a process of seeking and interpreting evidence for use by learners and their teachers to decide where the learners are in their learning, where they need to go and how best to get there" (Assessment Reform Group, 2002, p. 2). Because research concerning new media in language assessments is still in its infancy, an emphasis on immediate pedagogical goals is warranted. 


\section{Computer-Assisted Language Learning and Testing}

One way to gain a background in the use of new media in assessment is to review developments in computer-assisted language learning (CALL) over the last few decades (Levy, 1997; Chapelle, 2001; Levy \& Stockwell, 2006). In general, work in CALL has run alongside that in applied linguistics, most notably in its move from a behaviorist perspective of language learning to a cognitive view, and now to a social approach to language learning, teaching, and assessment (Delcloque, 2000). Nowadays, CALL is widely defined as "the full integration of technology in language learning" consisting of a "dynamic complex in which technology, theory, and pedagogy are inseparably interwoven" (Garrett, 2009, pp. 719-20).

To foster the integration of new media, large educational organizations have established standards for the pedagogical use of digital technologies (e.g., International Society for Technology in Education, 2012). With specific regard to language learning, the Teachers of English to Speakers of Other Languages (TESOL) established a technology standards framework (Healey et al., 2009) to set out baseline expectations for both learners and instructors. The aim of these technology standards is to promote "pedagogically solid ways of integrating and using technologies in all language classrooms" (p. 1). Briefly, a summary of intended goals of the TESOL technology standards includes:

1. to acquire and maintain foundational skills and knowledge in technology for professional purposes;

2. to integrate pedagogical knowledge and skills with technology to enhance language teaching and learning;

3. to apply technology in record keeping, feedback, and assessment; and

4. to use technology to improve communication, collaboration, and efficiency.

Perhaps somewhat counterintuitively, the use of new media is both increasing and disappearing in language education as they become more and more mainstream and are simply blended into the routine practices of everyday teaching (Gruba \& Hinkelman, 2012).

Another way to gain insights into new media use is to understand developments in computer-based language testing. Chapelle and Douglas (2006) provide a comprehensive overview of the area. Following a historical overview (Burstein, Frase, Ginther, \& Grant, 1996), they identify the presence of technology throughout many aspects of language teaching and assessment, and note that a persistent concern for researchers has been "whether or not test takers' apprehension about computer use might affect their language performance" (p. 17). Such worries are fading, Chapelle and Douglas point out, as current students report that the lack of computer use may inhibit their performance; indeed, as Douglas and Hegelheimer (2007) argue, simple paper and pencil tests may now appear to be antiquated and irrelevant to an increasing number of language students.

In their work, Chapelle and Douglas (2006, p. 23) set out the advantages and limitations of workstation computers with regard to test method characteristics. Efficiency and convenience are seen to be two key advantages; practical 
limitations of use may include the cost, location, and availability of appropriate workstations for test administration, and issues related to test security and the verification of candidate identification.

Importantly, discussion of the potential of technologies to influence construct definitions is prominent throughout language assessment research (Chapelle, 2008). Constructs, or the target concept that defines what is to be measured, have long been framed in terms of "traditional media" that include black-and-white print for reading, face-to-face interactions for speaking, audiotapes for listening, and handwritten products for writing (Gruba, 2006). With the growing use of new media in language programs, Royce (2007) argues for a greater recognition of "multimodal communicative competence" as a way to better acknowledge an understanding of the role of intersemiotic elements in textual comprehension and lead students to "becoming competent in interpreting and constructing appropriate meanings multimodally" (p. 374).

When new media are used as modes of presentation as well as in the production and demonstration of student learning, theorists argue for a fundamental shift in the view of assessments (Wyatt-Smith \& Cumming, 2009). Studies involving the role of digital video in second language listening assessment may help to illustrate some of the issues that arise through the use of new media. Based on the analysis of verbal report protocols of Australian learners attending to Japanese news videotexts, Gruba (2006) found that understanding of the foreign medium was best seen as variations of "play"; that is, rather than rely on traditional audiocentric definitions of listening, it was more helpful to conceptualize learner interactions with digital media as variations of curiosity, puzzlement, and engagement. Across a series of studies that compared "audio-only" versions with videotext formats in listening assessments, Wagner (2008) questioned ways to define listening when a multimodal medium was used as a mode of presentation. More recently, Cross (2011) showed how multimodal elements of a news broadcast in English were attended to by pairs of Japanese learners. Cross found that the multimodal elements facilitated comprehension in a variety of ways, but notably such elements could also inhibit the processing of audio content as they triggered differing expectations and inferences. Collectively, such studies point to the need to disentangle the complex interplay among learner abilities, technical affordances, and multimodal texts as a way to refine, or even to redefine, language constructs with sufficient clarity that they can be used in assessment designs (Ockey, 2009).

Assessment specialists have created both computer-based and computer-adaptive test designs. In the former, the workstation computer is seen as a platform equivalent to, but more efficient than, paper and pencil formats; in the latter, computer software responds to candidate input to continually adjust the selection and presentation of tasks to a calibrated level of language proficiency. López-Cuadrado, Armendariz, Latapy, and Lopistéguy (2008) explain the fundamentals of computeradaptive tests. In brief, task designs are grounded on the probability that candidate responses will align with the particular values associated with given psychometric characteristics, or parameters, that have been established in a model of the language construct. The complexity of the model, then, can vary depending on the range of traits under examination. Variations in the design complexity can be expressed in terms such as assisted self-adapted tests, testlet-based models, and tests with content 
balancing. At its core, computer-adaptive test development research seeks to arrive at a measurement of language ability through a calibration of the candidates' dynamic interpretations of material in light of their reported language-learning achievements, age, gender, learning styles, and attitudes (López-Cuadrado et al., 2008).

In summary, knowledge of both CALL and computer-based testing provides a background for understanding the complexities for creating new media assessments. At present, language assessment specialists employ networked workstations to deliver computer-based, or in some cases computer-adaptive, tests that meet the requirements of reliable, valid, and efficient examinations. The successful development of large-scale, high stakes examinations such as the Test of English as a Foreign Language Internet-based test (TOEFL iBT) (www.ets.org/toefl) demonstrates the ability to use computers in the assessment of listening, reading, speaking, and writing skills in testing centers throughout the world.

The use of new media in language assessments adds to the complexities of instrument design, particularly with regard to construct definition and the separation of candidate abilities from device capability. Within the current literature, computer-based instruments remain the focus of attention. Development of valid and reliable instruments demands significant resources and teams of disciplinary experts. For these reasons, it is prudent to first examine new media use in low stakes settings in which assessment for learning is a primary goal.

\section{Assessment 2.0, Multiliteracies, and Mobility}

According to Elliott (2008), the role of technology in assessment can be characterized in ways that correspond to the use of the Internet. Briefly, in Web 1.0 site designs, users are allowed to access and download material that cannot be altered, as is often the case for government policy Web sites; in Web 2.0 designs, users are encouraged to interact with tools on the site that enable them to post their own productions, write and exchange comments, or merge elements from other online sites. Web 2.0 designs include social network sites such as Facebook, Twitter, and YouTube, and are increasingly used for "telecollaboration" for a wide range of language-learning contexts and purposes (Guth \& Helm, 2010).

Akin to the static nature of Web 1.0 sites, Assessment 1.0 designs are formally administered, are paper- or workstation-based, are given at specific times and locations, and focus on individual performance. At the next incremental stage, Assessment 1.5 designs are based on a range of $e$-assessments that are workstationbased and enable candidates to demonstrate their abilities in online simulations, as is found in virtual chemistry labs. Additionally, e-assessment design allows students to contribute work to online portfolios, conduct reviews of peer work, or interact in established virtual communities (e.g., Crisp, 2007). Efforts to develop Assessment 1.5 designs can be found at sites that include, for example, Assessment Futures (http://www.iml.uts.edu.au/assessment-futures/index.html), Transforming Assessment (www.transformingassessment.com), or the Central Michigan University Assessment Toolkit (https://academicaffairs.cmich.edu/ caa/assessment/resources/toolkit.shtml). 
Elliot (2008) foresees Assessment 2.0 designs, not yet realized, as those that would involve measures of performances through extensive interactions with social network sites, provide opportunities to both access and post original productions, and allow for unrestrained navigation across global networks; that is, in such assessments, uses would mimic ways in which the Web is currently used. Importantly, Assessment 2.0 designs would place a strong emphasis on independent learning, collaboration, and the demonstration of higher order cognitive skills such as those that involve deep and complex problem solving. The challenges of Assessment 2.0, as Elliot (2008) writes, are both large and familiar: limited digital literacies among students and instructors, a lack of criteria for evaluating new communicative practices, difficulties in pinpointing individual contribution to group assessments, and the demands of equipping efforts to meet a rapidly changing plethora of new technologies.

Research concerning the comprehension of multimodal texts, learning in digital environments, and the intersections of literacy and technology can be found in topic areas such as media literacy, new literacies, and multiliteracies (for an overview see, e.g., Coiro et al., 2008). Briefly, new literacies scholars in education discuss the pedagogical implications inherent in the use of new media and foresee the need for a wholesale change in many established ways of teaching, learning, and assessment. As theorists argue, the growing use of new media must spur the design of innovative assessments that can better account for the complex interactions that are woven into the everyday communicative practices of the current generation of students (Brown, Lockyer, \& Caputi, 2010).

Grounded in work to do with literacy in the age of new media, Kress (2009) discusses the implications of a growing awareness of multimodality in studies of interactions and meaning. Two urgent questions for educators, according to Kress, arise from this point: "How do we assess learning expressed in multimodal texts, objects and processes?" and "What theories are needed to deal with assessment in this environment?" (p. 19; italics in the original). For Kress, assessment attempts to reconcile the relationship between what is expected to be learned and what is actually learned. To be assessed, learning must first be "recognized" by an assessor; when learners utilize modes and processes that lie outside the normal boundaries of recognition, their work may not be well understood or legitimized and thus they may seem to fail to produce any evidence of achievement. Ideally, Kress writes, any theory of assessment would take it into account that valuation happens with regard to all actions within all environments. For assessors, Kress argues, the implications of coming to recognize the signs of learning in new media environments lead to a choice: On the one hand, assessors can attend to the "metrics of conformity" or, on the other hand, assessors can strive to evaluate the "principles of semiotic engagement" (p. 37).

Adding to the challenges of Assessment 2.0 designs and the recognition of multimodal learning, the mobility of new media devices disrupts the security and control of workstation environments. Presently, language assessors direct candidates to sit for examinations at specified times and locations, and to make use of computers with particular configurations of hardware and software. Theoretically, the reasons candidates sit at secure sites and computers is to meet the demands of test designers, not to take the test itself. As mobile devices, including smart- 
phones, laptop computers, and multitouch tablet computers, become near ubiquitous and more powerful, their use is "converging" to shift the locus of power from the producer to the consumer (Jenkins, 2006). In the near future, perhaps, test candidates will ask: "Why do we need to travel to a particular location to use a particular device at a particular time of day?"

To see how assessment specialists and others are investigating such tensions, we now turn to current research.

\section{Challenges}

Extensive searches of the literature found few investigations concerning the use of new media in language assessments. To date, I would argue that research has focused on the potentialities and affordances of new media in language assessments through the conduct of small-scale, descriptive studies that have been situated in single-site classrooms or related educational settings. For example, Blake, Wilson, Cetto, and Pardo-Ballester (2008) found that variations in their measures of oral proficiency were caused by the use of different technologies. On a similar note, Miyazoe and Anderson (2010) found that student attitudes and learning outcomes varied when students wrote online in a forum, blog, or wiki as writing styles varied in line with the differing media. Further, O'Dowd (2010) explores the assessments of telecollaborative activities, arguing that they need to better align with social Web 2.0 practices to result in a determination of varying levels of intercultural awareness, new literacies, and multimodal language competence. As O'Dowd argues, language educators have to consider ethical, practical, and pedagogical dimensions of assessing telecollaboration. For the moment, O'Dowd suggests, language educators can make greater use of principled and appropriate rubrics to assess a range of student work that can be embodied in online portfolios.

Douglas (2010) imagines a time in the near future when candidates are directed to interact with sophisticated avatars within immersive virtual worlds in ways that probe aspects of language proficiency. Language-learning initiatives in virtual worlds have flourished since the early 2000s; again, I would argue, much of the empirical research concerning interaction in virtual worlds has focused largely on discourse features (e.g., Herring, in press), pedagogical approaches (e.g., Collentine, 2011), or both rather than on assessment concerns. Intended for use in higher education, sites such as Transforming Assessment provide regular online discussions and Webinars about the development of assessments for virtual worlds across a range of disciplines. To my knowledge, no framework yet exists that can underpin the development of new media language assessments.

It would be fair to suggest, I would argue, that assessment professionals have directed their attention to the development of computer-based instruments that are designed to meet the demands of test efficiency, reliability, and validity. For their part, scholars concerned with CALL and new literacies practices have generally set aside matters to do with assessment of language proficiencies. Because of the growing integration of new media throughout society and education, as well as an increased awareness of the new literacies agenda, research on and 
development of new media language assessments will no doubt draw much greater attention in the near future. From this point, I set out a series of challenges that I think will arise in the development of new media language assessments.

\section{Being Social}

New media are often associated with social media, in which frequent interactions are fostered across a range of social network sites, micro-blogging facilities, and smartphone applications. McNamara and Roever (2006) have set out a broad agenda for the role of social concepts in language assessment, and ask, for example, whether social dimensions of language proficiency are testable. Issues to do with the assessment of discourse and pragmatics come to the fore in social settings. Practical concerns include timely completion and an ability to score performances with little expense. One way to address such issues would be to produce fiveminute videoconferences between assessors and candidates. The clips of the recorded sessions could then be hosted on a server for distribution and scoring by experienced raters, and later archived on backup systems to meet legal concerns. The way forward, McNamara and Roever suggest, is to move beyond assessing aspects of pragmatics in isolation while remaining clear about what elements are to be specifically examined.

\section{Defining Constructs}

One recurring theme is that language assessments that make use of new media and technologies may require both a reworking of established constructs and an identification of emerging ones to better acknowledge candidate performances of new literacies. The traditional language construct definitions of reading, writing, listening, and speaking require fundamental reconsideration and may best be seen as complex variations of "multimodal communicative competence" (Royce, 2007).

Consider the assessment of online writing in sites that involve a wiki, mash-up, or micro-blogging. Factors such as willingness to collaborate, fluency, grammatical accuracy, and key social discourse markers may be taken into account. In addition to such factors, it may be challenging to distinguish candidate computer literacy skills from contribution to the collaboration as well as from an ability to produce coherent writing. When the use of new media results in large variations in the production and reception of language, such as in the case of speaking into a smartphone to create a written message, the traditional understanding of what is to be measured shifts; thus, to separate what is truly "language" and what are the technical capabilities of users and their devices will challenge language assessors.

\section{Evaluating New Media Language Assessments}

Chapelle and Douglas (2006) pointed out that because computer-based versions of language assessments differed from paper and pencil instruments, they required a different set of evaluation standards. Accordingly, new media assessments will differ from those designed to be used on computer workstations, and thus a third set of evaluation criteria will be needed. All language assessments 
should be evaluated on sound theoretical and practical principles, and guidelines identified by Chapelle and Douglas (2006) offer a strong basis.

\section{Access and Equity}

Dooey (2008) discusses a range of challenges that may accompany the transition to a new era of language assessments. Importantly, Dooey reminds assessment professionals of access and equity issues for candidates who may come from lowtechnology educational settings such as those in developing countries. As a solution, Dooey recommends that paper and pencil versions be maintained and be made available for high stakes tests. Legal or ethical requirements, such as those outlined in the Web Access Initiative (www.w3.org/WAI), encourage the creation of designs for inclusion that may be challenging for technology-mediated instruments to meet. Institutional operability to share resources and reduce costs can also be included in designs (see, for example, IMS Global Learning Consortium, www.imsglobal.org).

\section{Security and Verification}

The mobile and configurable nature of new media devices will heighten concerns surrounding candidate verification and test security. Such issues have arisen in other areas of network-based interactions, including those for legal and medical records (e.g., Klosek, 2011), and assessment professionals will also be pressed to deliver solutions that are secure as well as cost-effective, user-friendly, and fit for purpose.

Devices with biometric capabilities are becoming more prevalent, and the verification of a candidate identity may eventually lead to biometric scans that have, to date, been the stuff of science fiction movies. Unique individual physical attributes related to a series of physical characteristics, of the face in particular, will be the focus of many security measures for identity (Gates, 2011). During actual use, security for mobile devices raises such a wide range of risks that new architectures may be needed to handle the challenges (see, e.g., Rouse, 2012). Such challenges include, for example, a need to maintain the persistence of communication between the computers serving assessments and the receiving devices, and the need to detect interruptions or out-of-boundary variations in individual performance (e.g., differing rhythms in typing) as possible alerts for security breaches.

\section{Training Assessment Professionals}

Currently situated within applied linguistics, and often trained in language teaching, quantitative research, and aspects of project management, language assessment professionals will increasingly need to understand fields as diverse as human-computer interaction, artificial intelligence, and computational linguistics. Clearly, the combination of economic pressures (loss of clientele, loss of markets, and increased competition) and the shifting nature of language use and performance will force language assessment design to become increasingly complex and multidisciplinary. Future teams of professionals, perhaps configured virtually for 
short-term projects, will need to involve software engineers, systems engineers, lawyers, e-security experts, and human-computer interaction specialists to work with assessment specialists. Chapelle (2008) sees a need to enhance graduate-level training with a focus on an understanding of software tools, particularly in the areas of natural language processing and automatic speech recognition (Chapelle \& Chung, 2010).

In the short term, assessments for learning intended for use within formal language programs will be designed and delivered through institutional learning management systems, and perhaps served to devices such as multitouch tablet computers, laptops, and smartphones. In the establishment of hardware specifications for the institution, language educators will need to insist that the typing of non-roman characters be enabled through the provision of a piece of software known as an input method editor. Under the auspices of the institute perhaps, legal requirements for accessibility within new media assessment designs may be more easily met.

\section{Future Directions}

If assessment is seen to lead the language curriculum, the lack of development in new media assessments could well prevent educators from encouraging students to produce work in digital forms that are likely to dominate in coming generations. Looking to future directions, language assessment specialists will eventually have to contend with the rise in new literacies. For Kress (2009), a choice must be made between the "metrics of conformity" and the "principles of social engagement." In short, how are second language proficiencies to be demonstrated, and recognized, in 21st-century learners?

Ironically, as a push for standardized testing grows, so too does the push in educational systems to adopt innovative assessment solutions that meet the needs of the 21st century (Wyatt-Smith \& Cumming, 2009).

Workstation-based instruments, now established, will continue to be the platform for large-scale language testing research; in the near future, it is likely that innovative and well-resourced institutes will foster the development of new media assessments. Assessment for learning, rather than an assessment of learning (Gardner, Harlen, Hayward, \& Stobart, 2008; Gipps \& Stobart, 2003), could help to expand emerging frameworks on classroom-based assessment (Hill \& McNamara, 2012. As a preliminary research agenda, I would suggest that this needs to deliver four key outcomes: (1) an understanding of the appropriate conditions that may foster the uptake of new media assessments within institutional language programs, (2) principled designs of new media in language assessments, (3) empirical investigation of student uses of new media assessments, and (4) an evaluation and diffusion of new media assessments in institutional practices. Delivery of these outcomes would make a significant contribution to the current body of research.

The purpose of the initial stage of the research agenda would be to investigate the influences of new media use and adoption in the wider institutional context. Instructor decisions concerning assessment, and learner perceptions of assess- 
Table 60.1 Summary of research on the institutional context

\begin{tabular}{|c|c|c|}
\hline Area of inquiry & Research techniques & Focal questions \\
\hline $\begin{array}{l}\text { Survey of institutional } \\
\text { policies regarding } \\
\text { language assessment }\end{array}$ & $\begin{array}{l}\text { Online quantitative } \\
\text { survey }\end{array}$ & $\begin{array}{l}\text { What are the general perceptions } \\
\text { of the role of new media and } \\
\text { technologies in language } \\
\text { assessment practices? }\end{array}$ \\
\hline $\begin{array}{l}\text { Institutional supports } \\
\text { for innovation }\end{array}$ & $\begin{array}{l}\text { Semistructured interviews } \\
\text { with information } \\
\text { technology (IT) support } \\
\text { staff; document analysis }\end{array}$ & $\begin{array}{l}\text { In what ways does the institute } \\
\text { actively promote educational } \\
\text { innovation, especially with regard } \\
\text { to the use of new media in } \\
\text { assessment? }\end{array}$ \\
\hline $\begin{array}{l}\text { Institutional } \\
\text { expectations of } \\
\text { academic staff }\end{array}$ & $\begin{array}{l}\text { Semistructured interviews } \\
\text { with heads of school and } \\
\text { subject coordinators; } \\
\text { document analysis }\end{array}$ & $\begin{array}{l}\text { How do the criteria for promotion } \\
\text { workload expectations, and } \\
\text { opportunities for professional } \\
\text { development influence innovation } \\
\text { in assessment? }\end{array}$ \\
\hline
\end{tabular}

Table 60.2 Summary of research on principled designs

\begin{tabular}{lcl}
\hline Area of inquiry & Research techniques & \multicolumn{1}{c}{ Focal questions } \\
\hline $\begin{array}{l}\text { Construct definitions for } \\
\text { language assessment }\end{array}$ & $\begin{array}{l}\text { Semistructured } \\
\text { interviews }\end{array}$ & $\begin{array}{l}\text { What are the general perceptions of the } \\
\text { role of new media and technologies in } \\
\text { language assessment practices? }\end{array}$ \\
Participatory designs & Use models & $\begin{array}{l}\text { How do various experts, from teachers } \\
\text { to assessment specialists, contribute to } \\
\text { co-designed new media assessments? }\end{array}$ \\
\hline
\end{tabular}

ments, do not take place in a vacuum. What institutional factors are there, if any, that both enable and constrain the integration of new media into existing language assessments? See Table 60.1.

In a second phase, an agenda would seek to establish a clear assessment use argument as the basis of new media assessment, and involve stakeholders in making a series of informed choices to build strong designs that could differentiate among candidate proficiencies (Bachman \& Palmer, 2010). In this stage, we first interview assessment specialists and language instructors concerning assessment goals, construct definitions, and fit-for-purpose factors. In the second phase, participatory design techniques (Cardenas-Claros \& Gruba, 2010) could help to bring together complementary teams of experts to co-create preliminary new assessments (see Table 60.2).

Although it is clear that a move to be innovative is a driving force in the ascendency of technology use in language programs, little work has been done on the view of second language learners concerning new media assessment practices. One key aspect of an agenda, then, is to examine how learners respond to new media assessment tasks. Responses are important to build theory that accounts for the influence of one media effect over another (see Table 60.3). 
Table 60.3 Summary of research of learner perception and use of new media assessments

\begin{tabular}{|c|c|c|}
\hline Area of inquiry & Research techniques & Focal questions \\
\hline $\begin{array}{l}\text { Computer literacy } \\
\text { skills }\end{array}$ & $\begin{array}{l}\text { Quantitative surveys; } \\
\text { semistructured } \\
\text { interviews }\end{array}$ & $\begin{array}{l}\text { What computer literacy skills are required } \\
\text { of learners such that Web } 2.0 \text { technologies } \\
\text { pose no barriers to the use of new media } \\
\text { in language assessment? }\end{array}$ \\
\hline $\begin{array}{l}\text { Perception of } \\
\text { innovative } \\
\text { assessment tasks }\end{array}$ & $\begin{array}{l}\text { Quantitative surveys; } \\
\text { semistructured } \\
\text { interviews }\end{array}$ & $\begin{array}{l}\text { What skills do you think are being } \\
\text { assessed with the use of these new } \\
\text { media? How do you rate the tasks? }\end{array}$ \\
\hline $\begin{array}{l}\text { Work with new } \\
\text { media assessment } \\
\text { tasks }\end{array}$ & $\begin{array}{l}\text { Immediately } \\
\text { retrospective and } \\
\text { delayed verbal report } \\
\text { protocols }\end{array}$ & $\begin{array}{l}\text { What test-taking strategies do candidates } \\
\text { employ under test conditions? }\end{array}$ \\
\hline
\end{tabular}

Table 60.4 Summary of the integration and evaluation of new media assessments

\begin{tabular}{|c|c|c|}
\hline Area of inquiry & Research techniques & Focal questions \\
\hline $\begin{array}{l}\text { Change } \\
\text { management }\end{array}$ & $\begin{array}{l}\text { Focus group sessions; } \\
\text { semistructured } \\
\text { interviews }\end{array}$ & $\begin{array}{l}\text { In your opinion, has the innovation using } \\
\text { new media assessment been successful? } \\
\text { Why or why not? }\end{array}$ \\
\hline $\begin{array}{l}\text { Diffusion of } \\
\text { innovation }\end{array}$ & $\begin{array}{l}\text { Focus group sessions; } \\
\text { semistructured } \\
\text { interviews }\end{array}$ & $\begin{array}{l}\text { Why, and how, have stakeholders made use } \\
\text { of recommendations for the integration of } \\
\text { new media into assessment practices? }\end{array}$ \\
\hline $\begin{array}{l}\text { Social shaping of } \\
\text { technologies }\end{array}$ & $\begin{array}{l}\text { Focus group sessions; } \\
\text { semistructured } \\
\text { interviews }\end{array}$ & $\begin{array}{l}\text { How have stakeholders adapted and } \\
\text { modified innovations to fit local needs and } \\
\text { the context of use? }\end{array}$ \\
\hline $\begin{array}{l}\text { Program } \\
\text { evaluation }\end{array}$ & $\begin{array}{l}\text { Document analysis; } \\
\text { semistructured } \\
\text { interviews }\end{array}$ & $\begin{array}{l}\text { In what ways have innovations been } \\
\text { integrated into the language curriculum, } \\
\text { and to what effect on stakeholders? }\end{array}$ \\
\hline
\end{tabular}

As Chapelle (2007, p. 30) asks: "How can those who are investing significant resources into learning and teaching be shown that innovation might be for the best?" At this stage of the agenda, program evaluation framework would motivate work with a range of stakeholders, with attention directed not only to new media assessments but also to change management, the diffusion of innovation, and the social shaping of technologies (see Table 60.4).

Given the complexity of the area, investigations in the near future need to remain small-scale, descriptive, and situated in "assessment for learning" contexts as a way to establish the groundwork for later, large-scale instrument designs and administrations. The core challenge is to identify and isolate the measurement of language proficiency in a digital environment where wide ranges of choices and options conflate the inter-related effects of multimodal texts, mobile technologies, and individual abilities.

Eventually, I would argue, work on computer-based testing must dovetail with work on new media language assessments, for a number of reasons. First and 
foremost, test developers must create instruments that meet the lifestyle demands of a global generation accustomed to near-ubiquitous digital access and interaction; that is, test candidates will come to expect to take assessments on their own mobile devices at a time and location of their own choosing. Second, as mainstream education adopts digital assessments, language educators will need to maintain a similar rate of adoption to remain relevant and current. Finally, the constructs of language use and performance are shifting under the influence of new media use, and language instrument design will need to align with such shifts to remain valid.

SEE ALSO: Chapter 36, Computer-Assisted Language Testing; Chapter 40, Portfolio Assessment in the Classroom; Chapter 44, Peer Assessment in the Classroom; Chapter 45, Test Development Literacy; Chapter 46, Defining Constructs and Assessment Design; Chapter 94, Ongoing Challenges in Language Assessment

\section{References}

Assessment Reform Group. (2002). Assessment for learning: 10 principles. Retrieved June 22, 2012 from http:/ / assessmentreformgroup.files.wordpress.com/2012/01/10principles_ english.pdf

Bachman, L. F., \& Palmer, A. S. (2010). Language assessment practice: Developing language assessments and justifying their use in the real world. Oxford, England: Oxford University Press.

Bennett, R. (2002). Inexorable and inevitable: The continuing story of technology and assessment. Journal of Technology, Learning, and Assessment, 1(1), 1-24.

Blake, R., Wilson, N., Cetto, M., \& Pardo-Ballester, C. (2008). Measuring oral proficiency in distance, face-to-face, and blended classrooms. Language Learning and Technology, 12(3), $114-27$.

Brown, I., Lockyer, L., \& Caputi, P. (2010). Multiliteracies and assessment practice. In D. R. Cole and D. R. Pullen (Eds.), Multiliteracies in motion (pp. 191-206). London, England: Routledge.

Burstein, J., Frase, L., Ginther, A., \& Grant, L. (1996). Technologies for language assessment. Annual Review of Applied Linguistics, 16, 240-60.

Cardenos-Claros, M., \& Gruba, P. (2010). Bridging CALL and HCI: Input from participatory design. CALICO Journal, 27(3), 576-91.

Chapelle, C. A. (2001). Computer applications in second language acquisition: Foundations for teaching, testing, and research. Cambridge, England: Cambridge University Press.

Chapelle, C. A. (2007). Challenges in evaluation of innovation: Observations from technology research. Innovation in Language Learning and Teaching, 1(1), 30-45.

Chapelle, C. A. (2008). Utilizing technology in language assessment. In E. Shohamy \& N. H. Hornberger (Eds.), Encyclopedia of language and education. Vol. 7: Language testing and assessment, (2nd ed., pp. 123-34). New York, NY: Springer.

Chapelle, C. A., \& Chung, Y.-R. (2010). The promise of NLP and speech processing technologies in language assessment. Language Testing, 27(3), 301-15.

Chapelle, C. A., \& Douglas, D. (2006). Assessing language through computer technology. Cambridge, England: Cambridge University Press.

Christ, W. G. (2004). Assessment, media literacy standards, and higher education. American Behavioral Scientist, 48(1), 92-6. 
Coiro, J., Knobel, M., Lankshear, C., \& Leu, D. J. (Eds.). (2008). Handbook of research on new literacies. New York, NY: Erlbaum.

Collentine, K. (2011). Learner autonomy in a task-based 3D world and production. Language Learning and Technology, 15(3), 50-67.

Crisp, G. (2007). The e-assessment handbook. London, England: Continuum.

Cross, J. (2011). Comprehending news videotexts: The influence of the visual content. Language Learning and Technology, 15(2), 44-68.

Delcloque, P. (2000). A history of CALL. Retrieved June 22, 2012 from http:/ / www.eurocalllanguages.org/resources/history_of_call.pdf

Dooey, P. (2008). Language testing and technology: Problems of transition to a new era. $\operatorname{ReCALL}, 20(1), 21-34$.

Douglas, D. (2010). Understanding language testing. London, England: Hodder.

Douglas, D., \& Hegelheimer, V. (2007). Assessing language using computer technology. Annual Review of Applied Linguistics, 27, 115-32.

Elliott, R. (2008). Assessment 2.0. International Journal of Emerging Technologies in Learning, 3(0). RetrievedJuly13,2011 fromhttp:/ / online-journals.org/i-jet/article/view/553/506

Gardner, W., Harlen, W., Hayward, L., \& Stobart, G. (2008). Changing assessment practice: Process, principles and standards. Retrieved October 18, 2012 from http://issuu.com/ debseed/docs/aria-english

Garrett, N. (2009). Computer-assisted language learning trends and issues revisited: Integrating innovation. Modern Language Journal, 93(s1), 719-40.

Gates, K. (2011). Our biometric future: Facial recognition and the culture of surveillance. New York, NY: New York University Press.

Gipps, C., \& Stobart, G. (2003). Alternative assessment. In W. Harlen (Ed.), Student assessment and testing. Vol. 2 (pp. 89-102). Los Angeles, CA: Sage.

Gruba, P. (2006). Playing the videotext: A media literacy perspective on video-mediated L2 listening. Language Learning and Technology, 10(2), 77-92.

Gruba, P., \& Hinkelman, D. (2012). Blending technologies in the second language classroom. Basingstoke, England: Palgrave Macmillan.

Guth, S., \& Helm, F. (Eds.). (2010). Telecollaboration 2.0: Language, literacies, and intercultural learning in the 21st century. New York, NY: Peter Lang.

Healey, D., Hegelheimer, V., Hubbard, P., Ioannou-Georgiou, S., Kessler, G., \& Ware, P. (2009). TESOL technology standards framework. Alexandria, VA: TESOL.

Herring, S. C. (in press). Discourse in Web 2.0: Familiar, reconfigured, and emergent. In D. Tannen \& A. M. Tester (Eds.), Georgetown University Round Table on Languages and Linguistics 2011: Discourse 2.0: Language and new media. Washington, DC: Georgetown University Press. Retrieved 17 March, 2012 http://ella.slis.indiana.edu/ herring/ GURT.2011.prepub.pdf

Higgins, C. (Ed.). (2011). Identity formation in globalizing contexts. Berlin, Germany: De Gruyter.

Hill, K., \& McNamara, T. (2012). Developing a comprehensive, empirically based research framework for classroom-based assessment. Language Testing, 29(3), 395-420.

International Society for Technology in Education. (2012). ISTE.NETS: The standards for learning, leading, and teaching in the digital age. Retrieved June 22, 2012 from http:// www.iste.org/standards.aspx

Jenkins, H. (2006). Convergence culture: Where old and new media collide. New York, NY: New York University Press.

Klosek, J. (2011). Exploring the barriers to the more widespread adoption of electronic health records. Notre Dame Journal of Law, Ethics and Public Policy, 25(2), 429-45.

Kress, G. (2009). Assessment in the perspective of a social semiotic theory of multimodal teaching and learning. In C. Wyatt-Smith \& J. Cumming (Eds.), Educational assessment 
in the 21st century: Connecting theory and practice (pp. 19-42). Dordrecht, Netherlands: Springer.

Levy, M. (1997). Computer-assisted language learning: Context and conceptualization. New York. NY: Oxford University Press.

Levy, M., \& Stockwell, G. (2006). CALL dimensions: Options and issues in computer-assisted language learning. Mahwah, NJ: Routledge.

Lievrouw, L. A. (2011). Alternative and activist new media. Cambridge, England: Polity.

López-Cuadrado, J., Armendariz, A. J., Latapy, M., \& Lopistéguy, P. (2008). A genre-based perspective for the development of communicative computerized adaptive tests. Educational Technology and Society, 11(1), 87-101.

McNamara, T., \& Roever, C. (2006). Language testing: The social dimension. Malden, MA: Blackwell.

Miyazoe, T., \& Anderson, T. (2010). Learning outcomes and students' perceptions of online writing: Simultaneous implementation of a forum, blog, and wiki in an EFL blended learning setting. System, 38, 185-99.

Ockey, G. (2009). Developments and challenges in the use of computer-based testing (CBT) for assessing second language ability. Modern Language Journal, 93(s1), 836-47.

O'Dowd, R. (2010). Issues in the assessment of online interaction and exchange. In S. Guth \& F. Helm (Eds.), Telecollaboration 2.0: Language, literacies, and intercultural learning in the 21st century (pp. 337-60). New York, NY: Peter Lang.

Potter, J. (2011). Media literacy (5th ed.). Los Angeles, CA: Sage.

Rouse, J. (2012). Mobile devices: The most hostile environment for security? Network Security, 3, 11-13.

Royce, T. D. (2007). Multimodal communicative competence in second language contexts. In T. D. Royce \& W. Bowcher (Eds.), New directions in the analysis of multimodal discourse (pp. 361-90). New York, NY: Erlbaum.

Wagner, E. (2008). Video listening tests: What are they measuring? Language Assessment Quarterly, 5(3), 218-43.

Wyatt-Smith, C., \& Cumming, J. (Eds.). (2009). Educational assessment in the 21st century: Connecting theory and practice. Dordrecht, Netherlands: Springer.

\section{Suggested Readings}

Bakardjieva, M. (2012). Reconfiguring the mediapolis: New media and civic agency. New Media and Society, 14, 63-79.

Bax, S. (2012). Computer-assisted language testing. In M. Thomas, H. Reinders, \& M. Warschauer (Eds.), Contemporary computer-assisted language learning. London, England: Continuum.

Boud, D., \& Falchikov, N. (Eds.). (2007). Rethinking assessment in higher education: Learning for the longer term. Abingdon, England: Routledge.

Chapelle, C. A., Chung, Y.-R., Hegelheimer, V., Pendar, N., \& Xu, J. (2010). Towards a computer-delivered test of productive grammatical ability. Language Testing, 27, 443-69.

Flachikov, N., \& Thomson, K. (2008). Assessment: What drives innovation? Journal of University Teaching and Learning Practice, 5(1), 49-60.

Jewitt, C. (2012). Technology, literacy, learning: A multimodal approach. Hoboken, NJ: Taylor \& Francis.

Jones, R. H. H. (2012). Understanding digital literacies. Hoboken, NJ: Taylor \& Francis.

Kárpáti, A. (2009). Web 2 technologies for net native language learners: A "social CALL." $\operatorname{ReCALL}, 21,139-56$. 
Kimber, K., \& Wyatt-Smith, C. M. (2008). Assessing digital literacies: Can assessment ever be the same? In L. Unsworth (Ed.), New literacies and the English curriculum: Multimodal perspectives (pp. 328-52). London, England: Continuum.

Language Testing. (2010). 27(3). (Special issue largely devoted to concerns of automatic scoring).

Martinec, R., \& van Leeuwen, T. J. (2009). The language of new media design: Theory and practice. London, England: Routledge.

Pullen, D. L., \& Cole, D. R. (Eds.). (2010). Multiliteracies and technology enhanced education. Hershey, PA: IGI Global.

Thomas, M., \& Reinders, H. (Eds.). (2010). Task-based language learning and teaching with technology. New York, NY: Continuum.

Thorne, S. L., \& Black, R. (2008). Language and literacy development in computer-mediated contexts and communities. Annual Review of Applied Linguistics, 27, 133-60.

Thurlow, C., \& Mroczek, K. (2011). Digital discourse: Language in the new media. Oxford, England: Oxford University Press. 


\section{University Library}

\section{- M M N E R VA A gateway to Melbourne's research publications}

Minerva Access is the Institutional Repository of The University of Melbourne

Author/s:

Gruba, P

Title:

New Media in Language Assessments

Date:

2013

Citation:

Gruba, P. (2013). New Media in Language Assessments. John Wiley \& Sons, Inc..

Persistent Link:

http://hdl.handle.net/11343/241677 